\title{
Efeito da Suplementação de Metionina Sobre o Desempenho e a Avaliação de Carcaças de Frangos de Corte
}

\author{
Effect of Methionine Supplementation on Performance \\ and Carcass Yield of Broiler Chickens
}

Código / Code

0107

Autor(es) / Author(s)

Whitaker $\mathrm{HMA}^{1}$

Mendes $A A^{2}$

Garcia EA ${ }^{2}$

Roça $\mathrm{RO}^{3}$

Varolli Jr JC ${ }^{4}$

Saldanha EPB

1-Profa da Faculdade de Agronomia Luis Meneghel, Bandeirantes

2-Profo do DPEA-FM VZ/UNESP, Botucatu

3-Profo da Faculdade de Ciências Agronômicas/ UNESP, Botucatu

4-Profo da Universidade São Marcos, São Paulo

5-Pesquisador Científico do Instituto de Zootecnia de Nova Odessa , Brotas

\section{Correspondência / Mail Address}

Ariel Antonio Mendes

Depto. de Produção e Exploração AnimalFM VZ/UNESP

Caixa Postal, 560 - Distrito de Rubião Júnior 18.618-000 - Botucatu - SP - Brasil

E-mail: arielmendes@fca.unesp.br

Unitermos / Keywords

composição química, frangos de corte, metionina, rendimento de carcaça

broiler chickens, carcass yield, chemical composition, methionine

Observações / Notes

Este artigo é parte da tese de Doutorado do primeiro autor junto ao Curso de PósGraduação em Zootecnia da FM VZ/UNESP, Botucatu, SP

Agradecemos a Fapesp pela concessão de auxílio financeiro para execução do projeto (Processo N 96/9687-1).

\section{RESUMO}

Um experimento foi conduzido para avaliar os efeitos da suplementação de metionina em dietas de crescimento (22 a 42 dias de idade) sobre o desempenho, rendimento e composição química da carcaça de frangos de corte. Foram utilizados 2000 frangos de corte da linhagem comercial Ross, sexados, distribuídos em um delineamento ao acaso, em esquema fatorial 2 x 5 (sexo e níveis de metionina) com quatro repetições de 50 aves cada. As dietas foram formuladas para conter $100 \%, 110 \%, 120 \%, 130 \%$ e $140 \%$ dos níveis de metionina recomendados pelo NRC (1994). Aos 42 dias de idade, as aves foram abatidas para avaliar a quantidade de gordura abdominal, bem como 0 rendimento e a composição química da carcaça. Ao aumentar o nível de metionina da dieta, não houve efeito $(p>0,05)$ sobre o ganho de peso, consumo de ração, conversão alimentar, mortalidade, gordura abdominal, e rendimento de carcaça, bem como, umidade, proteína, gordura e cinzas do peito e pernas. Não foi verificado efeito $(p>0,05)$ de interação entre nível de metionina e sexo, mas as fêmeas apresentaram maior percentual de gordura abdominal $(p<0,05)$ que os machos. Como o nível de metionina não afetou o desempenho, rendimento e composição química da carcaça, concluiu-se que a recomendação sugerida pelo NRC (1994) de 0,38\% para frangos de corte no período de 22 a 42 dias de idade está adequada.

\section{ABSTRACT}

One experiment was conducted to evaluate the effect of dietary additional methionine levels during the grower period (22 a 42 days of age) on performance, carcass yield, and chemical composition of broiler chickens. Tw o thousand sexed Ross broilers, were reared in a randomized factorial $2 \times 5$ design (sex and methionine levels) with four replications of 50 birds each. Experimental diets were formulated to contain $100 \%$, $110 \%, 120 \%, 130 \%$ and $140 \%$ of methinine level suggested by NRC (1994). Methionine levels were, .38, .42, .46. .50 and .54\%, respectively. At 42 days of age birds were slaughtered to evaluate carcass yield, abdominal fat and chemical composition. Increasing methionine level did not affect ( $p>.05$ ) weight gain, feed consumption, feed conversion, mortality, abdominal fat, and carcass yield and breast and thigh moisture, protein, fat and ash.. Interaction between methionine level and sex was not significant $(p>.05)$, but females presented higher abdominal fat $(p<.05)$ than males. As methionine level did not affected performance and carcass yield and composition, it was concluded that the methionine level during grower period ( 22 to 42 days of age) suggested by NRC (1994) is adequate. 


\section{INTRODUÇÃO}

A comercialização de cortes desossados de aves vem aumentando bastante nos últimos anos, tanto no mercado interno como para exportação. Com isso, o rendimento de cortes nobres, como peito e coxas, além de carcaças com menor quantidade de gordura, passou ser crucial para a indústria. A fim de otimizar resultados, as empresas têm lançado mão de linhagens de alto rendimento e de programas de alimentação que maximizem o rendimento de carne de peito e de pernas. Além disso, normalmente os machos têm sido aproveitados para serem abatidos mais pesados a fim de serem destinados à desossa, enquanto as fêmeas são comercializadas na forma de carcaça inteira ou recortada. Embora nem sempre se utilizem rações específicas para machos e fêmeas, o calendário de troca de rações geralmente é alterado para contemplar as exigências nutricionais mais elevadas dos machos.

Tem sido observado que o conteúdo de proteína na dieta, a relação energia:proteína e os níveis de lisina, metionina e metionina + cistina afetam tanto o desempenho como a qualidade da carcaça de frangos de corte (Summers et al., 1992; M oran, 1994; Mendes et al., 1995; Baker et al., 1996; Bartov \& Plavnick, 1998; Albino et al., 1999; Pesti et al., 1999).

A metionina, na forma de S-adenosilmetionina, é o mais importante doador do radical metil no organismo, sendo exigida para a biossíntese de muitas substâncias importantes envolvidas no crescimento, como creatina, carnitina, poliaminas, epinefrina, colina e melatonina (Baker, 1991). Uma dieta deficiente em metionina reduz o ganho de peso, a eficiência alimentar e o teor de proteína na carcaça, além de estimular o consumo de ração, contribuindo com energia adicional e, conseqüentemente, ocasionando acréscimo na deposição de gordura corporal (Summers et al., 1992; M oran, 1994).

De acordo com o NRC (1994), os níveis de exigências de metionina e metionina + cistina para 0 período de 22 a 42 dias de idade são, respectivamente, $0,38 \%$ e $0,72 \%$. Rostagno et al. (2000) recomendam $0,45 \%$ de metionina em dietas com $3.000 \mathrm{kcal} / \mathrm{kg}$. Esses níveis são idênticos aos recomendados pelo NRC (1984) e são considerados baixos para maximizar o desempenho dos frangos de corte (Jensen et al., 1989; Mendonça \& Jensen, 1989; Hickling et al., 1990; Schutte \& Pack, 1995; Barboza et al., 1998; Albino et al.,1999). Alguns autores têm evidenciado que níveis altos de metionina reduzem a quantidade de gordura abdominal (Jensen et al., 1989; Schutte \& Pack, 1995; Albino et al., 1999) e aumentam o rendimento de carne do peito (Hickling et al., 1990; Gorman \& Balnave, 1995; Silva et al., 1996).

Tendo em vista que as exigências nutricionais das linhagens de frangos de corte atuais de alto rendimento são diferentes daquelas criadas há alguns anos, o objetivo do trabalho foi avaliar o efeito de níveis adicionais de metionina sobre o desempenho, rendimento e qualidade da carcaça de frangos de corte no período de 22 a 42 dias de idade, e verificar eventuais diferenças nas exigências de machos e fêmeas.

\section{MATERIAL E MÉTODOS}

O experimento foi conduzido na Faculdade de Medicina Veterinária e Zootecnia da UNESP, Campus de Botucatu, no período de 19 de junho a 31 de julho de 1997. Foram utilizados 2000 pintos de um dia, da linhagem Ross, sexados e vacinados no incubatório contra as doenças de Marek e Bouba Aviária. As aves foram alojadas em galpão experimental e distribuídas em 40 boxes, com capacidade para 50 aves cada um, em uma densidade de 10 aves / $\mathrm{m}^{2}$.

Na fase pré-experimental, de 1 a 21 dias de idade, os pintos foram criados sob condições tradicionais de manejo, recebendo ração com $21 \%$ de proteína bruta e $3000 \mathrm{kcal} / \mathrm{kg}$ de energia metabolizável, sendo que os níveis dos demais nutrientes foram estabelecidos de acordo com Rostagno et al. (1992). No período 22 a 42 dias de idade, os frangos receberam dietas isoprotéicas e isocalóricas com 19\% PB e $3150 \mathrm{kcal}$ $\mathrm{EM} / \mathrm{kg}$, calculadas para atender às exigências nutricionais preconizadas por Rostagno et al. (1992), com exceção da metionina, cujos níveis foram de $100 \%, 110 \%, 120 \%, 130 \%$ e $140 \%$ das recomendações do NRC (1994), correspondentes a $0,38 \% ; 0,42 \% ; 0,46 \% ; 0,50 \%$ e $0,54 \%$ de DLmetionina, respectivamente (Tabela 1 ).

Aos 22 dias, as aves foram pesadas individualmente e distribuídas nos diferentes tratamentos. Foram controlados o peso médio inicial, peso médio final, ganho de peso médio, consumo médio de ração, conversão alimentar e mortalidade. Os dados de temperatura foram registrados diariamente às oito horas, utilizando-se um termômetro de máxima e mínima instalado no interior do galpão. Para avaliação do rendimento de carcaça e cortes, retirou-se, aos 42 dias de idade, amostras ao acaso de quatro aves por boxe, sendo 16 por tratamento, as quais foram identificadas, individualmente, através de anéis numerados nas patas e submetidas a um jejum 
alimentar de oito horas, com água à vontade até o momento do carregamento.

As aves foram abatidas no abatedouro experimental de aves da FM VZ e as avaliações foram feitas com as carcaças não resfriadas em chiller. Para o cálculo de rendimento de carcaça, das partes e da percentagem de gordura abdominal, foi considerado o peso vivo obtido na plataforma de abate. Considerou-se como gordura abdominal aquela presente na região da cloaca e a aderida à moela.

Das aves utilizadas para a avaliação dos rendimentos de carcaça e das partes, retirou-se 4 aves por tratamento das quais foram separados filés do peito e da coxa, sem pele e sem gordura, colocados em saco plástico e armazenados em freezer para posterior análise da composição química. O material, após moagem, foi homogeneizado e amostras em duplicata foram retiradas para as determinações dos teores de umidade, proteína bruta, extrato etéreo e cinzas de acordo com a metodologia preconizada pela AOAC (1990).

$O$ delineamento utilizado foi ao acaso, em esquema fatorial $2 \times 5$ (sexo e nível de metionina). Para a análise estatística dos resultados, foi utilizado o programa intitulado Sistema de Análise Estatística e Genética (SAEG), segundo Euclydes (1983), através do arranjo fatorial e interações entre sexo e níveis de metionina. Dentro do fator nível de metionina, foi analisada a decomposição dos graus de liberdade dos tratamentos em polinômios ortogonais até o terceiro grau (Cochran \& Cox, 1957). Quando necessário, os pares de médias foram comparados pelo Teste de Tukey.

\section{RESULTADOS E DISCUSSÃO}

Os resultados das médias de peso inicial, peso final, ganho de peso, consumo de ração, conversão alimentar e mortalidade, são apresentados na Tabela 2. 0 aumento do nível de metionina nas dietas não afetou $(p>0,05)$ o desempenho dos machos e das fêmeas, sendo que interação entre o nível de metionina e o sexo das aves também não foi significativa ( $p>0,05)$.

Esses resultados são discordantes dos relatados da maioria das pesquisas, em que níveis mais altos de metionina e metionina + cistina influenciaram positivamente o ganho de peso, consumo de ração e a conversão alimentar (Jensen et al.,1989; M endonça \& Jensen, 1989; Schutte \& Pack, 1995; Barboza et al., 1998; Pesti et al., 1999). Apesar de ter sido sugerido que machos e fêmeas apresentam diferenças nas exigências nutricionais (Smith et al., 1998; Albino et al., 1999), os resultados desse estudo indicaram que ambos os sexos responderam de maneira similar às mudanças nos níveis de metionina das rações experimentais, concordando com as observações de Gorman \& Balnave (1995).

Pelo fato de a metionina regular o consumo, as exigências em metionina e aminoácidos sulfurados totais são maiores para a obtenção da eficiência máxima de utilização dos alimentos do que para otimizar o ganho de peso (Schutte \& Pack, 1995). Por outro lado, o excesso de metionina prejudica 0 desempenho (Edmonds \& Baker, 1987), provocando deaminação e excreção de nitrogênio, o que contribui para a excreção do primeiro aminoácido limitante, incrementando a sua exigência (Parr \& Summers, 1991). Han \& Baker (1993) observaram que níveis de metionina entre $1,0 \%$ e $4,0 \%$ acima do nível da dieta basal prejudicaram o ganho de peso, o consumo de ração e a eficiência alimentar. As respostas em ganho de peso, consumo de ração e eficiência alimentar aos excessos de aminoácidos dietéticos ocorrem mais em função do desequilíbrio dos aminoácidos do que pelos seus antagonismos (Edmonds \& Baker 1987).

Os resultados referentes aos rendimentos de carcaça, das partes e gordura abdominal são apresentados na Tabela 3. Os níveis adicionais de metionina nas rações não influenciaram $(p>0,05)$ os rendimentos de carcaça, peito, pernas, asas, dorso e gordura abdominal. Não houve interação significativa $(p>0,05)$ entre 0 nível de metionina e sexo.

Os resultados da composição química da carcaça são apresentados na Tabela 4. Não foi encontrado efeito significativo $(p>0,05)$ dos níveis de metionina, bem como da interação entre níveis de metionina e sexo para os teores de umidade, proteína, extrato etéreo e cinzas no peito e pernas. A ausência dos efeitos dos níveis adicionais de metionina, em relação ao nível recomendado pelo NRC (1994), sobre as características avaliadas nesse estudo, contrariam alguns resultados encontrados na literatura, nos quais os níveis mais altos aumentaram os rendimentos de carcaça e peito e reduziram a gordura abdominal (Jensen et al., 1989; Mendonça \& Jensen, 1989; Hickling et al., 1990; Gorman \& Balnave, 1995; Schutte \& Pack, 1995; Silva et al., 1996; Silva et al., 1997; Albino et al., 1999). Jensen et al. (1989) conduziram dois experimentos com níveis de metionina + cistina de 0,72\% (dieta basal), 0,78\% e 0,84\% e concluíram que o nível mínimo de $0,78 \%$ era necessário para o máximo crescimento no período de 21 a 42 dias. Esse resultado foi confirmado por Mendonça $\&$ Jensen 
(1989), que encontraram $0,80 \%$ de metionina + cistina na ração como sendo o nível que proporcionou um melhor ganho de peso e eficiência alimentar, bem como menor teor de gordura abdominal. Os autores sugeriram como inadequado o nível de $0,72 \%$ de metionina + cistina proposto pelo NRC (1984) para o período de 22 a 42 dias de idade. Barboza et al. (1998), determinando o requerimento de metionina + cistina dos 22 aos 42 dias de idade, verificaram que 0 aumento dos níveis na ração proporcionou melhorias no ganho de peso e na conversão alimentar e diminuição no consumo de ração, sugerindo como recomendação mínima $0,896 \%$ para os machos e $0,856 \%$ para as fêmeas.

Segundo o National Research Council (NRC, 1984), a exigência de metionina pode ser atendida exclusivamente pela metionina, enquanto a exigência em cistina pode ser suprida pela própria cistina ou pela metionina. Os níveis de metionina + cistina podem ser estabelecidos com base em que um mínimo de $50 \%$ dos aminoácidos sulfurosos devem ser supridos por metionina (Baker et al., 1996). Partindo deste mesmo raciocínio, Rostagno et al. (1992) relataram que exigência de metionina é de $0,39 \%$ para formulações de rações para frangos de corte machos ou mistos no período de 22 a 42 dias de idade. Para criação com separação de sexo, as exigências seriam de $0,40 \%$ para os machos e $0,38 \%$ para as fêmeas (Silva et al., 1996).

Tem sido relatado que as exigências de aminoácidos podem ser influenciadas pela idade da ave, teor de proteína na dieta, relação energia: proteína, sexo, genética e pelo balanço de aminoácidos. Nesse sentido, diferentes respostas podem ser obtidas nos rendimentos de carcaça e partes, bem como na composição química da carcaça (Mendes et al., 1993; Bartov \& Plavnik, 1998; Gous et al., 1999). É possível que a ausência de efeito de níveis mais elevados de metionina sobre 0 desempenho, rendimento e composição química da carcaça esteja relacionada a um eventual desbalanço de aminoácidos, como relatado por (Edmonds \& Baker, 1987), ou mesmo pelo fato de terem sido utilizados valores de tabela para a formulação das rações experimentais, considerando-se aminoácidos totais e não aminoácidos digestíveis.

Nesse estudo, a ausência de interação entre o nível de metionina e sexo para os parâmetros de rendimento de carcaça, partes, gordura abdominal e composição química da carcaça indicou que ambos os sexos responderam de maneira similar às exigências nutricionais de metionina, como verificado por Junqueira et al. (1998). Independentemente dos níveis adicionais de metionina, as fêmeas apresentaram maior percentual de gordura abdominal $(p<0,05)$ do que os machos, concordando com os resultados encontrados por outros autores (Mendes et al., 1993; Mendes et al., 1995; Albino et al., 1999; Gous et al., 1999). Isso ocorre devido, principalmente, devido à existência de adipócitos de maior tamanho em fêmeas e pelo metabolismo mais acelerado dos machos (M endes et al., 1995).

Os teores médios de extrato etéreo encontrados no peito e pernas foram $1,2 \%$ e $6,5 \%$, respectivamente. De acordo com Vieira (1999), carnes de peito têm teor muito baixo de gordura devido à reduzida necessidade de estocar energia nestes músculos. Entretanto, os depósitos de gordura sub-cutâneos, na cavidade abdominal e nas sobrecoxas são bastante acentuados, caracterizando regiões onde a reserva de energia é importante para o isolamento térmico e para facilitar as atividades físicas de longa duração.

\section{CONCLUSÕES}

0 aumento do nível de metionina na dieta no período de 22 a 42 dias de idade não afetou o desempenho e os rendimentos de carcaça, cortes principais e secundários, gordura abdominal e composição química da carcaça, para ambos os sexos, sugerindo que o nível de 0,38\% recomendado pelo NRC (1994) é adequado. 
Tabela 1 - Composição percentual da dieta basal.

\begin{tabular}{|c|c|}
\hline Ingredientes & $\%$ \\
\hline Milho moído & 66,83 \\
\hline Farelo de soja & 23,93 \\
\hline Farinha de carne e ossos & 5,00 \\
\hline Óleo de soja & 2,64 \\
\hline Calcário calcítico & 0,60 \\
\hline Sal & 0,30 \\
\hline Suplemento mineral ${ }^{1}$ & 0,10 \\
\hline Suplemento vitamínico² & 0,30 \\
\hline Inerte $^{3}$ & 0,16 \\
\hline DL-M etionina $(99 \%)$ & 0,08 \\
\hline L-Lisina $(78 \%)$ & 0,06 \\
\hline Total & 100,00 \\
\hline \multicolumn{2}{|l|}{ Composição calculada } \\
\hline Energia metabolizável (kcal/kg) & 3.150 \\
\hline Proteína bruta (\%) & 19,00 \\
\hline Metionina (\%) & 0,38 \\
\hline M etionina + cistina (\%) & 0,68 \\
\hline Lisina (\%) & 1,00 \\
\hline Triptofano (\%) & 0,48 \\
\hline Treonina $(\%)$ & 0,70 \\
\hline Arginina (\%) & 1,24 \\
\hline Cálcio (\%) & 0,90 \\
\hline Fósforo disponível (\%) & 0,43 \\
\hline
\end{tabular}

1- Níveis de garantia para premix mineral - M icromin - Composição por quilo do produto: M n - 78.000mg; Zn - 50.000mg; Fe - 50.000mg; Cu - 75.000mg; I - 750mg; antifúngico - 15g.

2- Níveis de garntia para o premix vitamínico - Composição por quilo do produto: ácido fólico - 233,75mg; ácido pantotênico - 4332,250mg; antioxidante - 5g; coccidiostático - 20g; colina - 99.975mg; niacina - 11633,75mg; promotor de crescimento - 13,33g; Se - 100mg; vitamina A - 2332,750Ul; vitamina $B_{1}$ - 533,20mg; vitamina $B_{12}$ - 3332,50mg; vitamina $B_{2}$ - 1666,25mg; vitamina $B_{6}$ - 866,45mg; vitamina $D_{3}$ - 500Ul; vitamina $\mathrm{E}$ - 4000Ul; vitamina $\mathrm{K}$ - 500mg; veículo Q.S.P.

3- Casca de arroz. 
Tabela 2 - Desempenho de frangos de corte alimentados com rações com diferentes níveis de metionina no período de 22 a 42 dias de idade.

\begin{tabular}{|c|c|c|c|c|c|c|c|}
\hline $\begin{array}{l}\text { Nível de } \\
\text { metionina (\%) }\end{array}$ & Sexo & Peso inicial (g) & Peso final (g) & Ganho de peso (g) & $\begin{array}{c}\text { Consumo } \\
\text { de ração (g) }\end{array}$ & $\begin{array}{l}\text { Conversão } \\
\text { alimentar }\end{array}$ & M ortalidade (\%) \\
\hline \multirow[t]{3}{*}{0,38} & Macho & 738 & 2565 & 1827 & 3520 & 1,94 & 1,48 \\
\hline & Fêmea & 681 & 2150 & 1469 & 2991 & 2,04 & 0,49 \\
\hline & Média & 710 & 2358 & 1648 & 3256 & 1,99 & 0,98 \\
\hline \multirow[t]{3}{*}{0,42} & Macho & 740 & 2546 & 1806 & 3439 & 1,90 & 1,85 \\
\hline & Fêmea & 669 & 2158 & 1490 & 2957 & 1,98 & 0,00 \\
\hline & M édia & 704 & 2352 & 1648 & 3198 & 1,94 & 0,92 \\
\hline \multirow[t]{3}{*}{0,46} & Macho & 745 & 2643 & 1898 & 3490 & 1,84 & 2,04 \\
\hline & Fêmea & 666 & 2124 & 1458 & 2966 & 2,05 & 1,04 \\
\hline & M édia & 706 & 2384 & 1678 & 3228 & 1,94 & 1,54 \\
\hline \multirow[t]{3}{*}{0,50} & Macho & 749 & 2616 & 1867 & 3442 & 1,86 & 1,50 \\
\hline & Fêmea & 670 & 2169 & 1499 & 2995 & 2,00 & 0,49 \\
\hline & M édia & 710 & 2392 & 1682 & 3218 & 1,93 & 1,00 \\
\hline \multirow[t]{3}{*}{0,54} & Macho & 745 & 2627 & 1882 & 3513 & 1,87 & 2,03 \\
\hline & Fêmea & 666 & 2192 & 1525 & 2978 & 1,96 & 1,03 \\
\hline & M édia & 706 & 2410 & 1704 & 3246 & 1,92 & 1,53 \\
\hline Metionina (\%) & & n.s. & n.s. & n.s. & n.s. & n.s. & n.s. \\
\hline C.V. $(\%)$ & & 1,94 & 1,95 & 2,82 & 1,56 & 3,27 & 32,56 \\
\hline
\end{tabular}

n.s. - não significativo pelo teste $F(p>0,05)$. 
Tabela 3 - Rendimento de carcaça e percentagem de gordura abdominal de frangos de corte alimentados com dietas com diferentes níveis de metionina no período de 22 a 42 dias de idade.

\begin{tabular}{|c|c|c|c|c|c|c|c|c|}
\hline $\begin{array}{l}\text { Nível de } \\
\text { metionina (\%) }\end{array}$ & Sexo & $\begin{array}{c}\text { Peso vivo } \\
\text { (g) }\end{array}$ & Carcaça (\%) & $\begin{array}{l}\text { Carne de } \\
\text { peito }(\%)\end{array}$ & $\begin{array}{c}\text { Carne de } \\
\text { pernas(\%) }\end{array}$ & $\begin{array}{l}\text { Asas } \\
(\%)\end{array}$ & $\begin{array}{c}\text { Dorso } \\
(\%)\end{array}$ & $\begin{array}{c}\text { Gordura } \\
\text { abdominal (\%) }\end{array}$ \\
\hline \multirow[t]{3}{*}{0,38} & Macho & 2558 & 69,35 & 15,94 & 15,08 & 8,76 & 17,18 & 2,66 \\
\hline & Fêmea & 2158 & 67,00 & 15,07 & 13,84 & 8,83 & 16,59 & 3,13 \\
\hline & M édia & 2358 & 68,17 & 15,50 & 14,46 & 8,80 & 16,88 & 2,90 \\
\hline \multirow[t]{3}{*}{0,42} & Macho & 2512 & 68,51 & 15,94 & 14,62 & 8,59 & 17,01 & 2,48 \\
\hline & Fêmea & 2208 & 69,73 & 16,23 & 14,64 & 9,03 & 17,46 & 2,77 \\
\hline & M édia & 2360 & 69,12 & 16,08 & 14,63 & 8,81 & 17,24 & 2,62 \\
\hline \multirow[t]{3}{*}{0,46} & Macho & 2438 & 69.98 & 16,37 & 15,18 & 8,63 & 17,12 & 2,56 \\
\hline & Fêmea & 2148 & 69.07 & 16,31 & 14,12 & 9,19 & 16,92 & 2,96 \\
\hline & M édia & 2292 & 69,52 & 16,34 & 14,65 & 8,91 & 17,02 & 2,76 \\
\hline \multirow[t]{3}{*}{0,50} & Macho & 2508 & 69,14 & 15,85 & 15,26 & 8,43 & 17,36 & 2,70 \\
\hline & Fêmea & 2145 & 69,26 & 16,15 & 14,24 & 8,96 & 17,40 & 3,22 \\
\hline & M édia & 2326 & 69,20 & 16,00 & 14,75 & 8,70 & 17,38 & 2,96 \\
\hline \multirow[t]{3}{*}{0,54} & Macho & 2500 & 68,65 & 15,98 & 14,28 & 8,56 & 17,49 & 2,77 \\
\hline & Fêmea & 2208 & 69,08 & 16,36 & 14,18 & 8,77 & 17,20 & 3,19 \\
\hline & M édia & 2354 & 68.06 & 16,17 & 14,23 & 8,66 & 17,34 & 2,98 \\
\hline Metionina (\%) & & n.s. & n.s. & n.s. & n.s. & n.s. & n.s. & n.s. \\
\hline C.V. $(\%)$ & & 1,39 & 1,13 & 5,54 & 1,88 & 1,65 & 1,60 & 6,83 \\
\hline
\end{tabular}

n.s. - não significativo pelo teste $F(p>0,05)$. 


\section{Efeito da Suplementação de Metionina Sobre o Desempenho e a Avaliação de Carcaças de Frangos de Corte}

Tabela 4 - Composição química da carcaça de frangos de corte alimentados com rações com diferentes níveis de metionina no período de 22 a 42 dias de idade.

\begin{tabular}{|c|c|c|c|c|c|c|c|c|c|}
\hline \multirow{2}{*}{$\begin{array}{l}\text { Nível de } \\
\text { metionina } \\
(\%)\end{array}$} & \multirow[t]{2}{*}{ Sexo } & \multicolumn{4}{|c|}{ Peito (\%) } & \multicolumn{4}{|c|}{ Pernas (\%) } \\
\hline & & Umidade & Proteína & $\begin{array}{l}\text { Extrato } \\
\text { etéreo }\end{array}$ & Cinzas & Umidade & Proteína & $\begin{array}{l}\text { Extrato } \\
\text { etéreo }\end{array}$ & Cinzas \\
\hline \multirow[t]{3}{*}{0,38} & Macho & 74,36 & 22,18 & 1,49 & 1,31 & 72,06 & 19,06 & 6,81 & 1,41 \\
\hline & Fêmea & 72,67 & 21,74 & 2,53 & 1,40 & 70,54 & 19,77 & 9,04 & 1,22 \\
\hline & M édia & 73,52 & 21,96 & 2,01 & 1,36 & 71,30 & 19,42 & 7,92 & 1,32 \\
\hline \multirow[t]{3}{*}{0,42} & Macho & 73,48 & 23,47 & 1,46 & 1,06 & 71,13 & 20,16 & 6,98 & 0,96 \\
\hline & Fêmea & 73,48 & 24,02 & 0,90 & 1,32 & 72,06 & 20,78 & 4,99 & 1,16 \\
\hline & M édia & 73,48 & 23,74 & 1,18 & 1,19 & 71,60 & 20,47 & 5,98 & 1,06 \\
\hline \multirow[t]{3}{*}{0,46} & Macho & 72,80 & 23,55 & 1,85 & 1,44 & 69,65 & 20,48 & 4,91 & 1,01 \\
\hline & Fêmea & 74,06 & 23,38 & 0,54 & 1,27 & 73,27 & 19,25 & 6,06 & 1,09 \\
\hline & M édia & 73,43 & 23,46 & 1,20 & 1,36 & 71,46 & 19,86 & 5,48 & 1,05 \\
\hline \multirow[t]{3}{*}{0,50} & Macho & 73,74 & 23,54 & 0,90 & 1,22 & 72,00 & 19,84 & 6,16 & 1,15 \\
\hline & Fêmea & 73,01 & 24,60 & 0,88 & 1,38 & 69,12 & 20,46 & 8,47 & 0,99 \\
\hline & M édia & 73,38 & 24,07 & 0,89 & 1,30 & 70,56 & 20,15 & 7,32 & 1,07 \\
\hline \multirow[t]{3}{*}{0,54} & Macho & 73,41 & 23,44 & 1,48 & 1,07 & 71,02 & 20,04 & 7,13 & 1,16 \\
\hline & Fêmea & 74,24 & 22,63 & 0,76 & 1,30 & 73,62 & 21,04 & 4,06 & 0,99 \\
\hline & M édia & 73,82 & 23,04 & 1,12 & 1,18 & 72,32 & 20,54 & 5,60 & 1,78 \\
\hline Metionina (\%) & & n.s. & n.s. & n.s. & n.s. & n.s. & n.s. & n.s. & n.s. \\
\hline C.V. $(\%)$ & & 1,24 & 6,26 & 31,17 & 12,79 & 3,17 & 8,07 & 22,68 & 20,48 \\
\hline
\end{tabular}

n.s. - não significativo pelo teste $F(p>0,05)$.

\section{REFERÊNCIAS BIBLIOGRÁFICAS}

Albino LFT, Silva SHM, Vargas JR JGV, Rostagno HS, Silva MA. Níveis de metionina + cistina para frangos de corte de 1 a 21 e 22 a 42 dias de idade. Revista Brasileira de Zootecnia 1999; 28(3):519-25.

Association of Official Analytical Chemists - AOAC Official methods of analysis. 15 ed. Arlington. 1990, 1094p.

Baker DH. Partitioning of nutrients for growth and other metabolic functions. Poultry Science 1991; 70:1797-805.

Baker DH, Fernandez SR, Webel DM, Parsons CM. Sulfur amino acid requirement and cystine replacement value of broiler chicks during the period three to six weeks post-hatching. Poultry Science 1996;75(6):737-42.

Barboza RJ, Albino LFT, Rostagno HS, Gomes PC, Hannas MI, Runho RC. Exigência de metionina + cistina para frangos de corte na fase de crescimento. In: Anais da $35^{\circ}$ Reunião Anual da Sociedade Brasileira de Zootecnia; 1998; Botucatu, SP. Brasil. p.469-71.
Bartov I, Plavnik I. Moderate excess of dietary protein increases breast meat yield of broiler chicks. Poultry Science 1998; 77:680-88.

Cochran WG, Cox GM. Experimental designs. New York, Willey, 1957. 611p.

Edmonds MS, Baker DH. Comparative effects of individual amino acid excess, when added to a corn-soybean meal diet: effects on growth and dietary choice in the chick. Journal of Animal Science 1987; 65:699-705.

Euclydes RF. Sistema para análises estatísticas e genéticas - SAEG. Universidade Federal de Viçosa-UFV, Viçosa, MG. Brasil. 1983, 59p.

Gorman I, Balnave D. The effect of dietary lysine and methionine concentrations on the growth characteristics and breast meat yields of Australian broiler chickens. Australian Journal of Agriculture Research 1995; 46:1569-77.

Gous RM, Moran JR. ET, Stilborn HR Bradford GD, Emmans GC. 
Evaluation of the parameters needed to describe the overall growth, the chemical grown, and the growth of feathers and breast muscles of broilers. Poultry Science 1999; 78:812-21.

Han $\mathrm{Y}$, Baker $\mathrm{H}$. Effects of excess methionine or lysine for broilers fed a corn - soybean meal diet. Poultry Science 1993; 72:1070-74.

Hickling D, Guenter W, Jackson ME. The effects of dietary methionine and lysine on broiler chicken performance and breast meat yield. Canadian Journal of Animal Science 1990; 70:673-68.

Jensen LS, Wyatt CL, Francher BI. Sulfur amino acid requirement of broiler chicks from 3 to 6 weeks of age. Poultry Science 1989; 68:163-68.

Junqueira OM, Araújo LF, Silva CS, Babosa MJB, Schaiti M, Sakomura NK. Níveis de lisina e metionina sobre o desempenho e rendimento de carcaça de frangos de corte na fase final de criação. In: Anais da Conferência Apinco de Ciência e Tecnologia Avícolas; 1998; Campinas, SP. Brasil. p.19.

Mendes AA, Gonzales E, Garcia EA, Varoli JC. Efeitos do nível nutricional da dieta e do sexo sobre o rendimento de carcaça de frangos de corte. Revista da Sociedade Brasileira de Zootecnia 1993; $22(3): 473-80$.

Mendes AA, Ancona LH, Laveaga AE, Franco JG. Efeito da relação energia: proteína da dieta sobre a gordura abdominal, gravidade específica e composição química da carcaça de frangos de corte. Veterinária e Zootecnia 1995; 7:41-48.

Mendonça CX, Jensen LS. Influence of protein concentration on the sulphur containing amino acid requirement of broiler chickens. Poultry Science 1989;30:889-98.

Moran ET. Response of broiler strains differing in body fat to inadequate methionine: live performance and processing yields. Poultry Science 1994; 73:1116-26.

National Research Council - NRC. Nutrient requirements of poultry. 8.ed., National Academic Press; 1984; Washington, D.C. 48p.

National Research Council - NRC. Nutrient requirements of poultry. 9.ed. National Academic Press; 1994; Washington, D.C. 155p.

Parr JF, Summers JD. The effects of minimizing amino acid excesses in broiler diets. Poultry Science 1991; 70:1540-49.

Pesti GM, Bakalli RI, Cervantes HM, Bafundo KW. Studies on semduramicin and nutritional responses: 2. Methionine levels. Poultry Science 1999; 78:1170-76.

Rostagno HS, Silva DJ, Costa PM A, Fonseca JB, Soares PR, Pereira JAA, Silva M A. Composição de alimentos e exigências nutricionais de aves e suínos. Tabelas Brasileiras. Viçosa, UFV.1992. 60p.

Rostagno HS, Albino LFT, Donzele JL, Gomes PC, Ferreira AS, Oliveira RF, Lopes DC. Composição de alimentos e exigências nutricionais de aves e suínos. Tabelas Brasileiras. Viçosa, UFV, 2000. 141p.
Schutte JB, Pack M. Sulfur amino acid requirement of broiler chicken from fourteen to thirty-eight days of age. 1. Performance and carcass yield. Poultry Science 1995; 74(3):480-87.

Silva MA, Albino LFT, Rostagno HS, Silva MA, Vargas JR JG. Rendimento de carcaça de frangos de corte em função dos níveis de proteína bruta e metionina + cistina na ração. In: Anais da $33^{\circ}$ Reunião Anual da Sociedade Brasileira de Zootecnia. Fortaleza; 1996; CE. Brasil. p.86-7.

Silva MA, Albino LFT, Rostagno HS, Silva MA, Vargas JR JG. Níveis de metionina + cistina e de proteína bruta para frangos de corte. Revista da Sociedade Brasileira de Zootecnia 1997; 26(2):350-56.

Smith ER, Pesti GM, Bakalli RI ware GO, M enten JFM. Further studies on the influence of genotype and dietary protein on the performance of broilers. Poultry Science 1998; 77:1678-87.

Summers JD, Sprati D, Atkinson JL Broiler weight gain and carcass composition when fed diets varying in amino acid balance, dietary energy and protein level. Poultry Science 1992; 71:263-73.

Vieira SL. Considerações sobre as características de qualidade de carne de frango e fatores que podem afetá-la. In: Anais da $36^{\circ}$ Reunião Anual da Sociedade Brasileira de Zootecnia; 1999; Porto Alegre, RS. Brasil. p.81-7. 